\title{
COMPARISON OF RESULTS BETWEEN CARTILAGE TYMPANOPLASTY AND TEMPORALIS FASCIA TYMPANOPLASTY.
}

1. MBBS, DLO

ENT Surgeon

Social Security Landhi Hospital Karachi.

2. MBBS, FCPS

Consultant Gynecologist Social Security Landhi Hospital Karachi.

3. MBBS, DLO, MS

ENT

Bakhtawar Amin Medical College Multan.

4. MBBS, DLO, FCPS

Professor ENT

Indus Medical College,

Tando Muhmmad Khan, Hyderabad.

5. MA (Speech Audiology)

Audiologist

Dow University of Health Sciences, Karachi.

Correspondence Address:

Dr. Tahir Hussain Khan

A1/41, Rizwan Society, Scheme 33,

University Road, Karachi.

tahirhussainkhan99@gmail.com

Article received on:

09/12/2019

Accepted for publication:

20/02/2020
Tahir Hussain Khan ${ }^{1}$, Humaira Tahir², Ashfaq Hussain Rana ${ }^{3}$, Sohail Malik ${ }^{4}$, Shahid Akhtar ${ }^{5}$

ABSTRACT... Objectives: To compare the results after performing cartilage tympanoplasty and temporalis fascia tympanoplasty. Study Design: Analytical/Observational study. Setting: Two different hospitals. Social Security Landhi Hospital Karachi and Al-Tibri Medical College \& Hospital Malir Karachi. Period: July 2017 to June 2018. Material \& Methods: 76 patients were included for this study with both genders who had dry tympanic membrane perforations after taking antibiotics. Age ranges between 18 to 40 years. Patients were divided into two groups, group-I and group-II. In group-I, temporalis fascia tympanoplasty performed under microscope with post aural approach and in group-II, tragal cartilage tympanoplasty performed with the oto-endoscope via permeatal approach. Results: Weber test performed on $1^{\text {st }}$ post-operated day, it was lateralized towards operated ear which indicate the safety of inner ear. Vomiting and vertigo not found after tympanoplasty in both groups which indicate the safety of vestibular system. There was no blood soaked guaze seen after tympanoplasty in group-Il (cartilage tympanoplasty). Bleeding was less in group-Il as compare to group-l. 37 patients out of 38 had intact grafted tympanic membrane in group-I while all (38) patients had intact grafted tympanic membrane in group-II. Mean duration of surgery was $65.1+3.7$ minutes in group-II (cartilage tympanoplasty) and mean duration of surgery was $82.0+5.6$ minutes in group-I (temporalis fascia tympanoplasty). $P$ value was $<0.001$ is significant. Duration of surgery was less in groupII. Hearing was also improved in both groups after tympanoplasty. Post-operated AB-gap reduction seen in all patients of both groups. Conclusion: Results of both temporalis fascia and cartilage tympanoplasty were almost same but cartilage tympanoplasty is better because it consumed less time, less post-operated bleeding and perception of pain were also less.

Key words: $\quad$ Cartilage Tympanoplasty, Pure Tone Audiometry, Temporalis Fascia Tympanoplasty.

Article Citation: Khan TH, Tahir H, Rana AH, Malik S, Akhtar S. Comparison of results between cartilage tympanoplasty and temporalis fascia tympanoplasty. Professional Med J 2020; 27(9):1915-1921. DOI: 10.29309/TPMJ/2020.27.09.4401

\section{INTRODUCTION}

Chronic suppurative otitis media is defined as it is an inflammatory condition of mucoperiosteal lining (epithelium) of middle ear cleft. Tympanoplasty is the most frequently performed ear surgery for repair of perforated tympanic membrane. ${ }^{1}$ Chronic suppurative otitis media is characterized by persistent or recurrent ear discharge for three months or more through perforation of tympanic membrane. ${ }^{2}$

Tympanoplasty is well established and standard procedure for closure (repair) of perforated tympanic membranes. ${ }^{3}$ There are three approaches for repair of perforated tympanic membrane. 1-Post aural. 2-End aural. 3-Permeatal or trans-canal. Different graft materials have been used for reconstruction of tympanic membrane i.e. tragal cartilage, temporalis fascia, fat and vein. Graft is used medial or lateral to perforated tympanic membrane. Medial grafting is called inlay technique and lateral grafting is called on-lay technique. ${ }^{4}$ Over last few years different continues efforts made by oto-laryngiologist to achieve better surgical results. In spite of various technical improvements in operating microscope, basic limitations of surgical field could not resolved, it provides straight line image only. While when we used rigid oto- endoscope, it resolved limitation and provide wide field of vision and every corner of middle ear cavity can be seen. In 1967 Mer and his colleagues were used first time endoscope in 
middle ear later endoscopes are being used in middle ear surgeries. ${ }^{5}$ Eavey was the first man who repaired small tympanic membrane perforation with cartilage graft. Rourke $\mathrm{T}$ et al followed same technique to close perforated tympanic membrane with the help of rigid endoscope. ${ }^{6}$

Success of tympanoplasty should be monitored with subjective and objective. Subjective includes 1-improvement in hearing. 2-absence of ear discharge. 3-absence of tinnitus, and Objective includes healing of perforations seen with oto-endoscope and improvement of hearing threshold demonstrated by PTA. ${ }^{7}$ Intra operative complications may occur in tympanoplasty including injury to cochlea with partial or total sensory hearing loss. ${ }^{2}$

\section{MATERIAL \& METHODS}

76 patients were participated in this study randomly from Social Security Landhi Hospital Karachi and Al-Tibri Medical College \& Hospital Karachi. Duration of Study was twelve months from July 2017 to June 2018. Patients were divided into two groups, group-I and group-II. 38 patients in each group. In group-I, Temporalis fascia tympanoplasty performed in Social Security Landhi Hospital via post-aural approach and in group-II, Cartilage tympanoplasty (tragal cartilage) performed in Al-Tibri Medical College \& Hospital via per-meatal approach. In group-I, microscope used for magnification while in group-II, oto-endoscope used.

\section{Surgical steps for cartilage tympanoplasty}

After all aseptic measure infiltrate xylocaine with adrenaline inner side of tragus.

- incision given and perichondrium elevated from cartilage, appropriate size cartilage excised.

- refreshed perforated tympanic membrane margin with needle and scissor.

- Tympanomeatal flap raised, filled middle ear cavity with gel foam, placed graft over gel foam, tympanomeatal flap reflected back, placed gel foam over the graft and packed external auditory canal with ribbon gauze soaked in antiseptic.

\section{Surgical steps for temporalis fascia tympanoplasty}

After all aseptic measure local anesthetic infiltrate in post aural region.

- Incision given behind the ear, temporalis fascia taken for graft.

- set microscope in external auditory meatus, perforated margin of tympanic membrane refreshed, tympanomeatal flap raised, placed the temporalis fascia graft over gel foam, flap reflected back and dressed external auditory canal and post aural wound.

Pure tone audiometry (PTA) advised preoperatively in each patients. After 2 months of surgery again PTA advised and compared it with pre-op PTA. In PTA air conduction (AC), bone conduction $(B C)$ and air bone gap (ABgap) measured. After performing surgery, very next day ( $1^{\text {st }}$ post-operated day) weber test done in all patients for checking the cochlear (inner ear) reservation. Vomiting, vertigo, pain and bleeding also noted on $1^{\text {st }}$ post-operated day. Pain and bleeding noted after 1 week, after 1 month and after 2 months. Integrity of grafted tympanic membrane noted with oto-endoscopic examination after 2 months and reduction of air bone gap also noted by PTA after 2 months.

\section{RESULTS}

For study purpose different variables used like bleeding, pain, discharge, vertigo, vomiting, weber test, PTA, Oto-endoscopic/Microscopic examination of grafted tympanic membrane and duration of surgery in both groups noted and compared.

Figure-1. Shows bleeding comparison in cartilage and temporalis fascia tympanoplasty. Blood soaked gauze found in 37 patients $(97.4 \%)$ out of 38 patients in temporalis fascia tympanoplasty while blood soaked gauze found in only 5 patients $(13.2 \%)$ in cartilage tympanoplasty. This result showed that Cartilage tympanoplasty consumed less time as compare to temporalis fascia tympanoplasty.

Figure-2. Shows air-bone gap reduction in Temporalis fascia and Cartilage tympanoplasty. 
AB-gap reduction seen in 37 patients (97.4\%) in group-I and in group-II, it was $100 \%$.

Table-I Shows perception of pain in temporalis fascia tympanoplasty and in cartilage tympanoplasty. On $1^{\text {st }}$ post-op. day 18 patients
(47.4\%) had no pain in group-II (Cartilage tympanoplasty) while in group-I, 8 patients (21.1\%) had no pain. Only 1 patient complaint moderate pain in cartilage tympanoplasty while it was in 4 patients in temporalis fascia tympanoplasty.

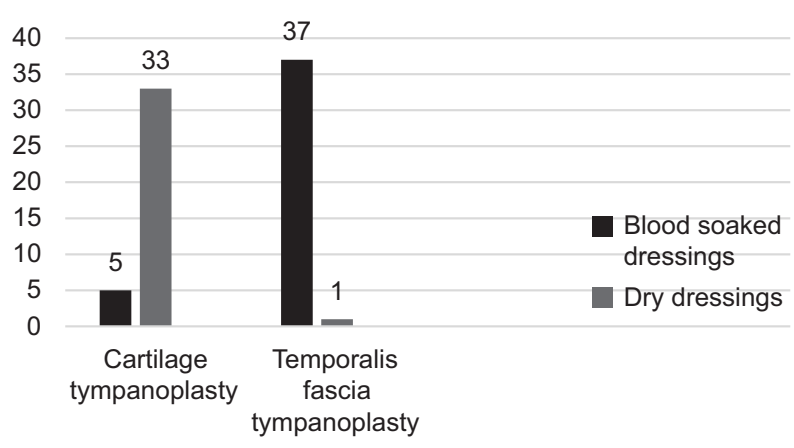

Figure-1. Showing bleeding comparison between cartilage tympanoplasty and temporalis fascia tympanoplasty

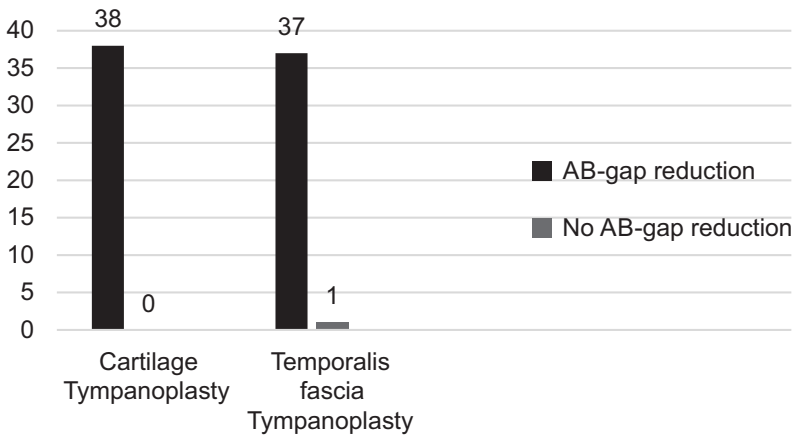

Figure-2. Showing AB gap reduction between cartilage tympanoplasty and temporalis fascia tympanoplasty

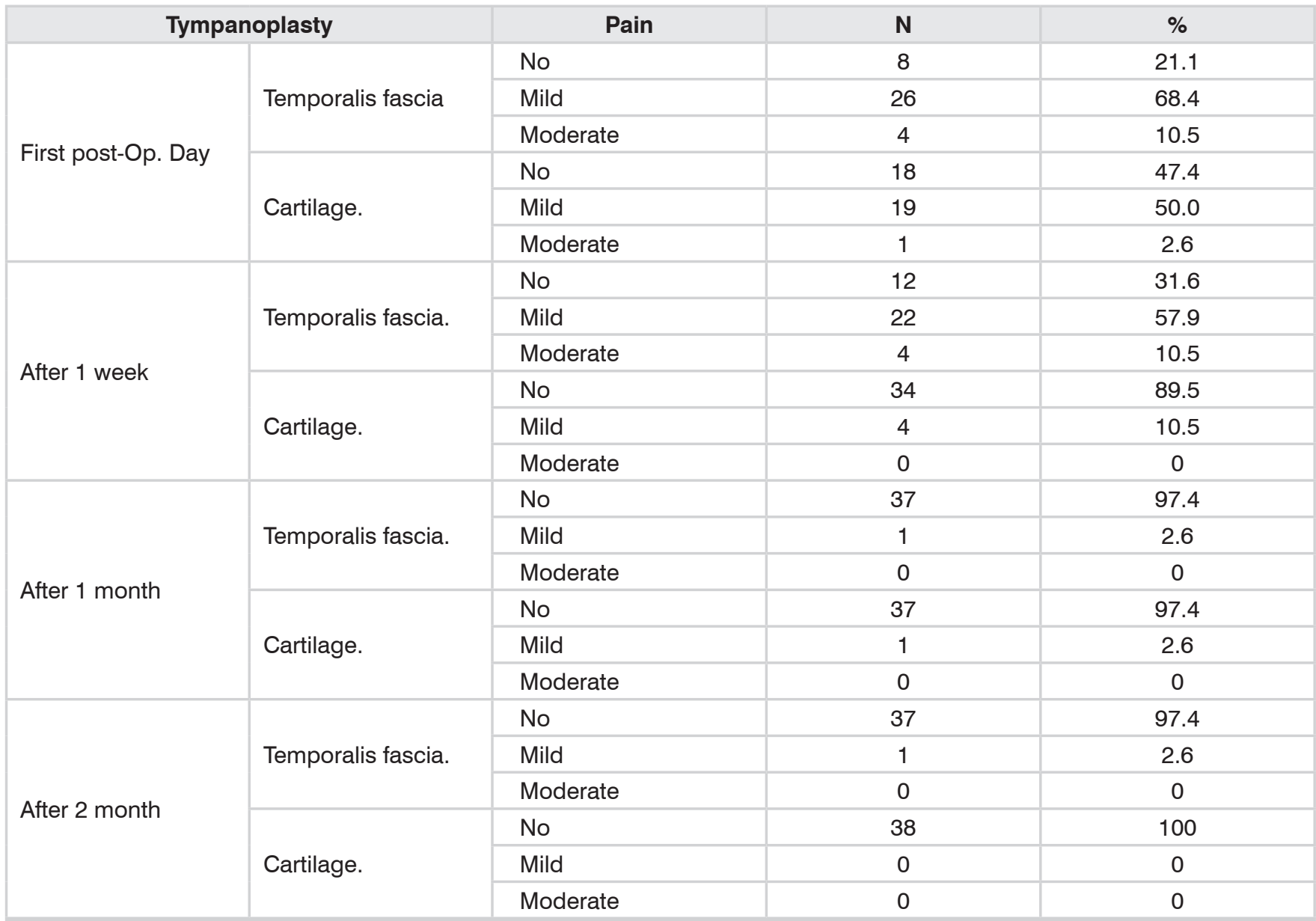

Table-I. Showing the comparison of pain in cartilage tympanoplasty and temporalis fascia tympanoplasty $(\mathrm{n}=78)$ 


\begin{tabular}{|c|c|c|c|c|c|}
\hline \multicolumn{3}{|c|}{ Tympanoplasty } & Mean (dB) & Std. Deviation & P-Value \\
\hline \multirow{6}{*}{$\begin{array}{l}\text { (Group-I) } \\
\text { Temporalis fascia } \\
\text { Tympanoplasty }\end{array}$} & \multirow{2}{*}{$\begin{array}{l}\text { Air Conduction } \\
\text { (dB) }\end{array}$} & Before Surg. & 42.0 & 2.526 & \multirow{2}{*}{$<0.001$} \\
\hline & & After Surg. & 26.74 & 2.596 & \\
\hline & \multirow{2}{*}{$\begin{array}{l}\text { Bone Conduction } \\
\text { (dB) }\end{array}$} & Before Surg & 12.87 & 2.195 & \multirow{2}{*}{0.793} \\
\hline & & After Surg. & 13.00 & 2.169 & \\
\hline & \multirow{2}{*}{$\begin{array}{l}+A-B \text { gap } \\
\text { (dB) }\end{array}$} & Before Surg. & 29.37 & 3.191 & \multirow{2}{*}{$<0.001$} \\
\hline & & After Surg. & 15.42 & 1.388 & \\
\hline \multirow{6}{*}{$\begin{array}{l}\text { (Group-II) } \\
\text { Cartilage } \\
\text { Tympanoplasty }\end{array}$} & \multirow{2}{*}{$\begin{array}{l}\text { Air Conduction } \\
(\mathrm{dB})\end{array}$} & Before Surg. & 42.68 & 2.055 & \multirow{2}{*}{$<0.001$} \\
\hline & & After Surg. & 27.18 & 1.872 & \\
\hline & \multirow{2}{*}{$\begin{array}{l}\text { Bone Conduction } \\
\text { (dB) }\end{array}$} & Before Surg. & 13.24 & 2.247 & \multirow{2}{*}{0.715} \\
\hline & & After Surg. & 13.05 & 2.130 & \\
\hline & \multirow{2}{*}{$\begin{array}{l}\text { A-B gap } \\
\text { (dB) }\end{array}$} & Before Surg. & 29.42 & 3.099 & \multirow{2}{*}{$<0.001$} \\
\hline & & After Surg. & 15.47 & 1.688 & \\
\hline
\end{tabular}

Table-II. Showing Pure tone audiometry, mean, standard deviation and $p$ value

\begin{tabular}{|l|c|c|c|}
\hline & $\begin{array}{c}\text { Cartilage Tympanoplasty } \\
(\mathbf{n = 3 8 )}\end{array}$ & $\begin{array}{c}\text { Temporalis Fascia } \\
\text { Tympanoplasty } \\
(\mathbf{n = 3 8 )}\end{array}$ & P-Value \\
\hline Duration of Surgery (mins) & $65.1 \pm 3.7$ & $82.0 \pm 5.6$ & $<0.001$ \\
\hline
\end{tabular}

Table-III. Showing duration of surgery in cartilage tympanoplasty and temporalis fascia tympanoplasty.

Mild pain found in 19 patients (50\%) in cartilage tympanoplasty while it was in 26 patients (68.4\%) in temporalis fascia tympanoplasty. Perception of pain were noted after 1 week, after 1 month and after 2 months, it was less in cartilage tympanoplasty as compare to temporalis fascia tympanoplasty.

Table-ll Shows result of PTA in both groups in which air conduction, bone conduction and $A B$ - gap noted before surgery and after surgery with standard deviation. P-value was $<0.001$ in both groups which was significant. Hearing was improved in both groups.

Table-III Shows comparison for duration of surgery in temporalis fascia tympanoplasty and in Cartilage tympanoplasty. Over all mean duration of surgery was $73.6+9.8$ minutes. In group-I, duration of surgery was $82.0+5.6$ minutes while in group-II, it was $65.1+3.7$ minutes. Duration of surgery was less in cartilage tympanoplasty.

Over all graft success rate was $75(98.7 \%)$. In group-I, success rate was $37(97.4 \%)$ while in group-II, graft success rate was $38(100 \%)$.
Weber test lateralized towards operated ear in all patients in both groups on very next day of surgery which indicate that ossicles of middle ear and vestibule-cochlear system were intact.

\section{DISCUSSION}

Bhushan $\mathrm{K}$ et al (2015) mentioned in his study that pre-operative hearing threshold was $45.69 \mathrm{db}$ while average post-operative hearing threshold was $27.69 \mathrm{~dB}$, the average gain was $18 \mathrm{~dB}$. The average pre-operative $A B$-gap was $32.44 \mathrm{~dB}$ and post-operative $A B$-gap was $14.44 \mathrm{~dB}$, average gain was $18 \mathrm{~dB} .{ }^{1}$ Our study co relate with this study in which average pre-operative hearing threshold was $42.34 \mathrm{~dB}$, post-operative hearing threshold was $26.5 \mathrm{~dB}$ and average $A B$-gap reduction was $13.95 \mathrm{~dB}$.

In a study Patel $\mathrm{J}$ et al described that average time consumed in endoscopic(cartilage tympanoplasty) was 75 minutes while it was consumed 90 minutes in microscopic(temporalis fascia tympanoplasty). ${ }^{4}$ In our study average time spent in cartilage tympanoplasty was $65.1+3.7$ minutes and in temporalis fascia tympanoplasty, it was $82.0+5.6$ minutes. 
Aftab A et al(2016) described in his study that time consumption was $49.76+3.18$ minutes in trans-canal endoscopic(cartilage) tympanoplasty while it was $72.15+2.56$ minutes in microscopic(temporalis fascia) tympanoplasty. Time duration for endoscopic (cartilage) tympanoplasty was shorter as compare to microscopic (temporalis fascia) tympanoplasty. Graft success rate was $88 \%$ in cartilage tympanoplasty (endoscopic) and it was $84 \%$ in temporalis fascia tympanoplasty (microscopic). ${ }^{8}$ Our study also corelating in which time spent in cartilage tympanoplasty was $65.1+3.7$ minutes.

In another study (2014) showed that mean preoperative air conduction was $35.3+2.78 \mathrm{~dB}$ and post-operated air conduction was $22.27+5.4 \mathrm{~dB}$. There was gain of $14 \mathrm{~dB}$ after surgery. All cases had excellent cosmetic outcome. ${ }^{9}$ This is also co relate with our study in which no visible scar after surgery in cartilage tympanoplasty group and average gain after tympanoplasty was $13.95 \mathrm{~dB}$.

Another study (2016) showed that graft success rate was $91.3 \%$ in cartilage tympanoplasty group and $68.9 \%$ in temporalis fascia tympanoplasty group. Graft success rate in cartilage group was significantly higher than temporalis fascia group. ${ }^{10}$ In our study average graft success rate was $98.7 \%$.

In a study published in(2017) mentioned that the mean pre-operative air bone gap was 22.7 $+6.96 \mathrm{~dB}$ and post-operative AB-gap was $8.9+$ $4.5 \mathrm{db}$, a significant decrease of AB-gap noted $p$ value was $<0.001$ showed significance. ${ }^{11}$

A study published in(2017) revealed that mean operative time of MT(temporalis fascia tympanoplasty) was $88.9+28.5$ minutes significantly longer than cartilage tympanoplasty $68.2+22.1$ minutes. Graft success rate was $92 \%$ and $95 \%$ in MT and ET. In ET group pre and postoperative AB-gap was $18.9+1.6 \mathrm{~dB}$ and $9.2+$ $1.4 \mathrm{~dB}$ respectively. ${ }^{12}$ Showed similar results with our study.

Choi $\mathrm{N}$ et al (2017) described in his study that mean operative time in MT(temporalis fascia) group was $88.9+28.5$ minutes and it was $68.2+$ 22.1 minutes in ET(cartilage) group, significantly lower in ET group. ET group showed $0.8+1.0$ of pain score and in MT group, it was

$1.5+1.3$ on $1^{\text {st }}$ day after surgery. ${ }^{13}$ In our research less time spent in cartilage tympanoplasty and perception of pain was also decreased.

\section{CONCLUSION}

Cartilage tympanoplasty is better than temporalis fascia tympanoplasty because it takes shorter duration of time, less bleeding during and after surgery due to minimal area of incision, less pain and no post operated visible scar although graft uptake and hearing improvement were also similar in both cartilage and temporalis fascia tympanoplasty.

Copyright $(20$ Feb, 2020.

\section{REFERENCES}

1. Bhushan K, Himani D, Joginder G, Vikas K, Yadav SPS, et al. Staining in Tympanoplasty; Is Methylene blue Rationale?. Glob J Oto. 2015; 1(2): 555557. DOI: 10.19080/GJO.2015.01.555557

2. Khatoon A, Rizvi M, Sultan A, Khan F, Sharma M, Shukla I, Khan HM. Chronic suppurative otitis media: A clinico-microbiological menace. Int J Res Med Sci. 2015 Aug; 3:1932-6.

3. Malik SA. Permeatal approach for tympanoplasty: Scar-less approach of external auditory canal integrity. JLUMHS. 2014 May; 13(02):76.

4. Patel J, Aiyer RG, Gajjar Y, Gupta R, Raval J, Suthar PP. Endoscopic tympanoplasty vs microscopic tympanoplasty in tubotympanic CSOM: A comparative study of $\mathbf{4 4}$ cases. Int J Res Med Sci. 2015 Aug; 3(8):1953-7.

5. Özgür A, Dursun E, Terzi S, Erdivanlı ÖÇ, Coşkun ZÖ, Oğurlu M, Demirci M. Endoscopic butterfly cartilage myringoplasty. Acta oto-laryngologica. 2016 Feb 1; 136(2).

6. Balasubramanian T, Venkatesan U. Endoscopic otology a supplement. Otolaryngology. 2012;2:1-25.

7. Al Anazy FH, Alobaid FA, Alshiha WS. Sensorineural hearing loss following tympanoplasty surgery: A prospective cohort study. The Egyptian Journal of Otolaryngology. 2016 Apr 1; 32(2):93. 
8. Aftab A, Shamsheer A, Shahab FH, Syed AH. A Prospective Study Comparing the Results of Endoscope Assisted Versus Microscope Assisted Myringoplasty. Glob J Oto. 2016;1(4):1-6.

9. Singh MN, Hamam PD, Lyngdoh NC, Priyokumar OS. Evaluation of hearing status in pre and postoperative endoscopic type 1 tympanoplasty and its influencing factors. Journal of Medical Society. 2014 Sep $1 ; 28(3): 166$.

10. Yegin $Y$, Çelik M, Koç AK, Küfeciler L, Elbistanlı MS, Kayhan FT. Comparison of temporalis fascia muscle and full-thickness cartilage grafts in type 1 pediatric tympanoplasties. Brazilian journal of otorhinolaryngology. 2016 Dec; 82(6):695-701.
11. Karatas $M$, Dogan $S$. Inlay butterfly cartilage tympanoplasty for large central perforations. The European Research Journal. 2017; 3(3):259-63.

12. Muzaffar R, Rafiq R, Naik SM. Endoscopic tympanoplasty and microscopic tympanoplasty: A comparative analysis. International Journal of Scientific and Research Publications, August 2017:7(8); 589-90.

13. Choi N, Noh Y, Park W, Lee JJ, Yook S, Choi JE, Chung WH, Cho YS, Hong SH, Moon IJ. Comparison of endoscopic tympanoplasty to microscopic tympanoplasty. Clinical and experimental otorhinolaryngology. 2017 Mar; 10(1):44.

\begin{tabular}{|c|c|c|c|}
\hline \multicolumn{4}{|c|}{ AUTHORSHIP AND CONTRIBUTION DECLARATION } \\
\hline Sr. \# & Author(s) Full Name & Contribution to the paper & Author(s) Signature \\
\hline 1 & Tahir Hussain Khan & $\begin{array}{l}\text { Contribution, Performed surgical } \\
\text { percedure and did research for } \\
\text { thesis writing. }\end{array}$ & \\
\hline 2 & Humaira Tahir & $\begin{array}{l}\text { Sammarized data and prepared } \\
\text { performa and taken signature on } \\
\text { protorma by patients. }\end{array}$ & \\
\hline 3 & $\begin{array}{l}\text { Ashfaq Hussain } \\
\text { Rana }\end{array}$ & Formatting and editing the article. & \\
\hline 4 & Sohail Malik & Supervised the research. & \\
\hline 5 & Shahid Akhtar & $\begin{array}{l}\text { Did hearing assessment before } \\
\text { and after surgical intervention of } \\
\text { all patients without fee. }\end{array}$ & \\
\hline
\end{tabular}

